\title{
Optimization of an Integrated Hybrid Onboard Charger with High Efficiency of MPPT Solar Charger for Sustainable Energy of 3-Wheel Solar E-Rickshaw and Electric Vehicles
}

\author{
${ }^{1}$ MEAS Saran, ${ }^{2}$ SRUN Channareth, ${ }^{3}$ UN Sokoeun, ${ }^{4}$ Son Tara, ${ }^{5}$ NY Virbora, ${ }^{6}$ SRIM Saravuth \\ ${ }^{1}$ Ph.D. Candidate of Energy Technology and Management (ETM), ITC, Phnom Penh, Cambodia \\ ${ }^{2,3} \mathrm{Ph}$.D. Candidate of Mechatronics and Information Technology (MIT), ITC, Phnom Penh, Cambodia \\ ${ }^{4,5,6}$ Bachelor Student of Electronic faculty of NPIC, Phnom Penh, Cambodia \\ E-mail IDs: ${ }^{1}$ saranagoldd@gmail.com, ${ }^{2}$ nareth16npic@gmail.com, ${ }^{3}$ us.oeun@gmail.com, ${ }^{4}$ sonthara2014@gmail.com, \\ nnyvirakbora@gmail.com, ${ }^{6}$ srimsaravuth@gmail.com
}

\begin{abstract}
In this paper, we study methodologies to improve the efficiency of MPPT solar boost converter (48V-10A) of the hybrid onboard charger (HOBC) for sustainable energy (SE) of 3-wheel Solar E-Rickshaw (3WSE-Rickshaw) and electric vehicles (EVs). Based on our application for the mini-electric vehicles (MEVs) or lowspeed electric vehicles (LSEVs) and e-rickshaw with the storage batteries voltage of only $48 \mathrm{~V}$. The auxiliary PV solar array lower than $500 \mathrm{~W}-40 \mathrm{Vis}$ recommended for use in this study. In this case, the voltage of solar PV is lower than the battery voltage. This means the $P V$ cannot charge to the battery system directly. A boost voltage circuit charger higher than $48 \mathrm{~V}$ is needed including a maximum power point tracking algorithm. To achieve the fastcharging option we provide three main methods of DC-DC boost topology, MPPT P\&O control algorithms, and constant current-constant voltage (CC-CV) controller. Also included is a charging data read-record graphic of the MPPT charging stage, constant voltage charging stage, and float charging stage (MPPT-CV-Float-Charging Stage). The data is used to express and analyze on battery charger's characteristics. Moreover, the magnetic circuit is a very important key design technique for storing and transferring energy in a power converter. A good design of magnetic inductor gives a better result in low power losses of magnetic coreloss (MCL), winding copper loss (WCL), and stable energy conversion.
\end{abstract}

Keywords: Hybrid OBC(HOBC), Sustainable Energy (SE), 3wheelSolar E-Rickshaw(3-WSE-Rickshaw), mini-electric vehicles (MEVs), low-speed electric vehicles (LSEVs)MPPTboost topology, MPPTP \& O algorithms, MPPT-CV-FloatCharging Stage, Magnetic Core Loss (MCL), Winding Copper Loss (WCL).

\section{INTRODUCTION}

In this application, the system diagram of the electric vehicles and E-rickshaw is shown in Fig.1. There are many key parts or key components including an on-board charger, charge port, DC-DC converter, traction battery package, electric traction motor, auxiliary battery, power electronics controller, transmission, and thermal system [1]. The electric vehicle is a great technology solution for clean energy with zero emissions, but it still has some problems with electric energy cost and charge time. The fast-charging system can be used for a short time charging but the equipment of this system is very expensive as a level3 on-board charger (L3OBC) and DC fast-charging station (DC-FCS). A simple and popular solution for EV customers is home charging with level1and level2 OBC (L1-L2 OBC) at nighttime (home charging) for 8 to 10 hours. This includes recharge at the workplace or other EVs parking charging stations.

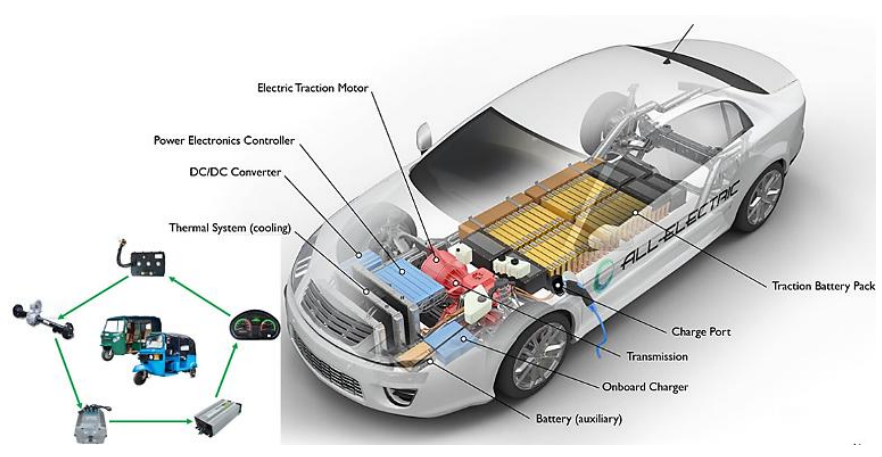

Figure 1: General Key components of EVs and E-rickshaw

The problem for level 1and level $2 \mathrm{EVs}$ systems is when we are driving a long way with low energy; there is not enough time for recharge energy on the mid-way. Since it takes a long time from 8 to 10 hours for a full charge. It's a big problem for EVs chargers with level1 and level 2.

The solution for EV's level 2 energy system is to add a solar PV array to achieve sustainable energy. Solar energy is commonly used as an extra energy system everywhere and everyday as a clean energy source, no emission, and free energy without paying extra money, and a comfortable driving experience for customers. Solar PV is a very good technology 
ISSN (online): 2581-3048

for EVs charging system as a hybrid onboard charger(HOBC)and can be added to a special sustainable energy system(SES) for all-electric vehicles(EVs).

In this study, we focus on a hybrid onboard charging system with MPPT Solar Boost Converter of 48V-10A as shown in Fig.2.Thevehicle to home (V2Home)or electric vehicle to home (EV2Home) as shown in Fig.3 is not a detailed discussion in this paper. The usage is to supply energy from vehicle to home or to load when a power outage or in an emergency.

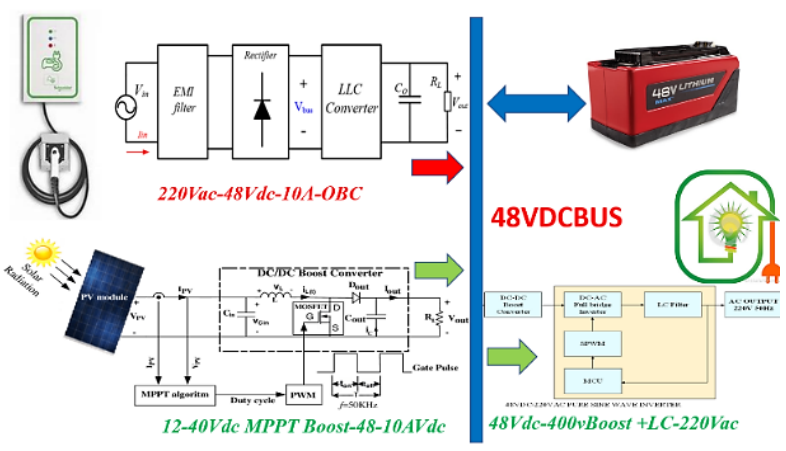

Figure 2: Hybrid OBC and vehicle to the home system

The main topic is a hybrid OBC charging system based on the high efficiency of an AC-DC onboard charger with DCDCMPPT boost solar charger output-48V-10A.In this task, we have a detailed discussion only on the method of highefficiency power tracking of MPPT boost solar charger with boost converter topology, the Perturb \& Observe MPPT algorithm is used. The Perturb and Observe (P\&O) tracking algorithm actively varies the current set-point, constant current-constant voltage output controller, a folding graphic of MPPT-CV-Float charging.

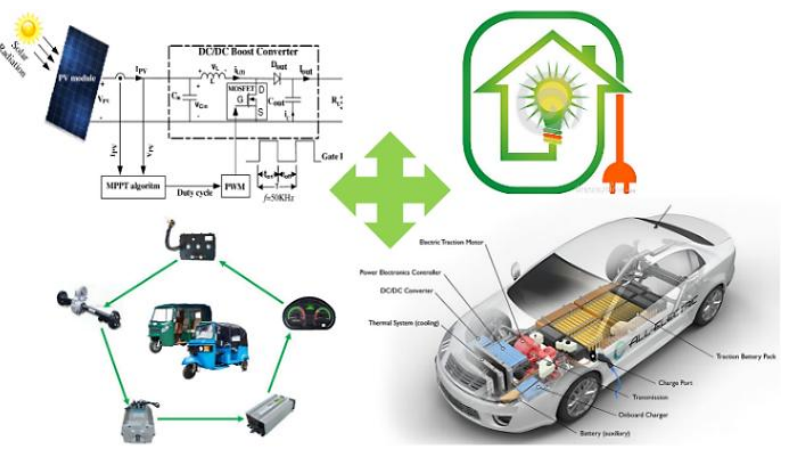

Figure 3: Solar Energy apply on E-rickshaw, EVs, and vehicles to home

\subsection{DC-DC Boost Topologies}

In application, DC-DC converters are used to convert DCinput-voltage to DC-output-voltage with a lot of topologies as shown in Fig.4. There are many conversion options like stepdown, step-up with single and interleave power inductors and other DC-DC converters that can produce a voltage in both steps, step-down and step-up depending on the duty cycle. If D $>50 \%$ the converter will start stepping up the output voltage and $\mathrm{D}<50 \%$ theconverter will start stepping down the output voltage with two power inductors. Some of the converters produce negative output as inverting buck-boost with single inductor winding \& Cuk converts with two inductors winding, and only two DC-DC topologies can be great step-up positive output voltage as SEPIC\& Boost Converter. But the SEPIC topology efficiency is less than $90 \%$,only the boost converters topologies, the efficiency ranging from $95 \%$ up to $99 \%$ with single and interleave power inductors[2-4].
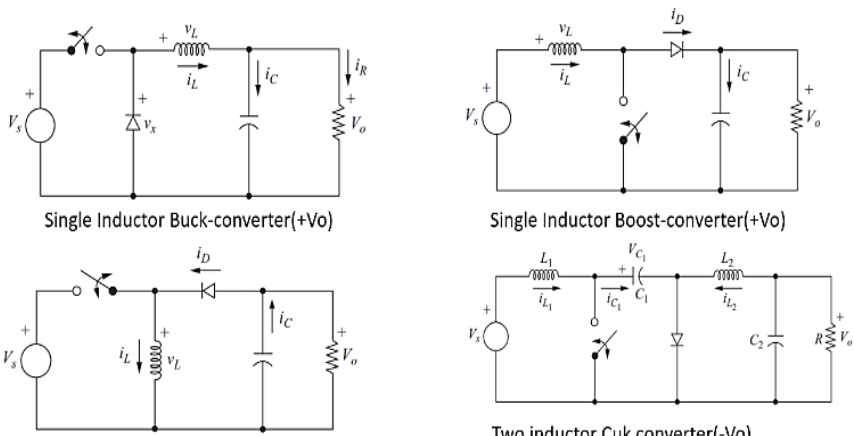

Single inductor buck-boost converter(-vo)

Two inductor Cuk converter(-Vo)
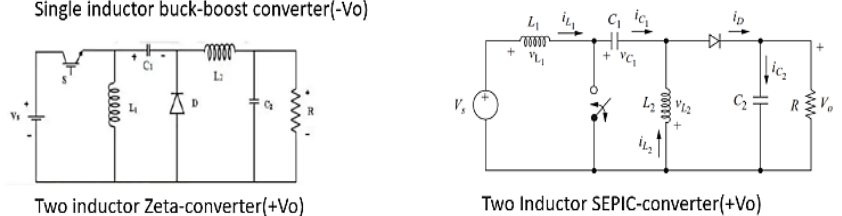

Two Inductor SEPIC-converter $\left(+V_{0}\right)$

Figure 4: DC-DC Converter topologies

\subsection{MPPT Control Algorithms}

Maximum power point tracking (MPPT) is an algorithm implemented on a photovoltaic (PV) converter to continuously adjust the impedance by tracking the solar arrays power to keep the PV system operating to the maximum power point (MPP) and maintaining the maximum output power while the solar irradiance, solar temperature changing through the day. The MPPT algorithm maintaining the output voltage to ensure that the PV system operates at the MPP (or peak voltage) on the solar PV's power and voltage curve, as shown in Fig.5.

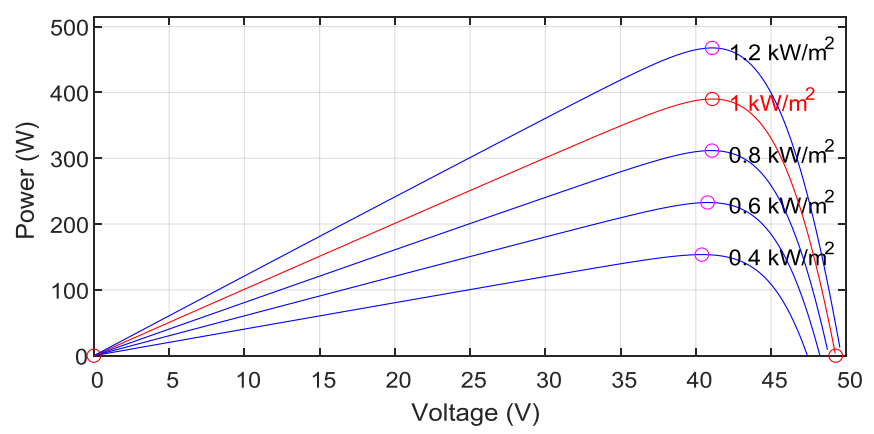

Figure 5: Power voltage curve with I-V and P-V characteristics of a photovoltaic system 
ISSN (online): 2581-3048

Volume 6, Issue 1, pp 77-87, January-2022 https://doi.org/10.47001/IRJIET/2022.601015

Microcontrollers are commonly used on implementing the MPPT algorithms. The control algorithms used in microcontrollers are to ensure the power tracking of the solar $\mathrm{PV}$ is maintaining at the maximum as possible during the changing of the solar irradiance and operating temperature [11]. The Perturbation and Observation ( $\mathrm{P} \& \mathrm{O})$ algorithm process the perturb operating voltage to ensure maximum power extracting from solar $\mathrm{PV}$, while there are several advanced and more optimized variants of this algorithm, a basic P\&O MPPT algorithm is shown in Fig.6.The incremental conductance (INC) algorithm, which is shown in Fig.7 compares the incremental conductance to the instantaneous conductance in a PV system. The process of this algorithm is to increases or decreases the output voltage until MPP is achieved. Unlike the P\&O algorithm, the voltage remains constant once MPP is reached, as shown in Fig.6. This algorithm is based on the principle that the maximum power point voltage is always a constant fraction of the opencircuit voltage. The open-circuit voltage of the cells in the photovoltaic array is measured and used as input to the controller.

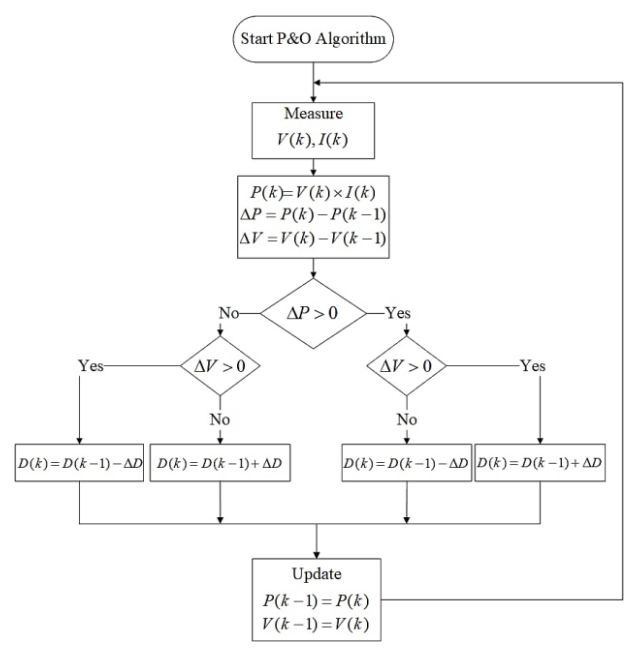

Figure 6: Basic P\&O algorithm [11]

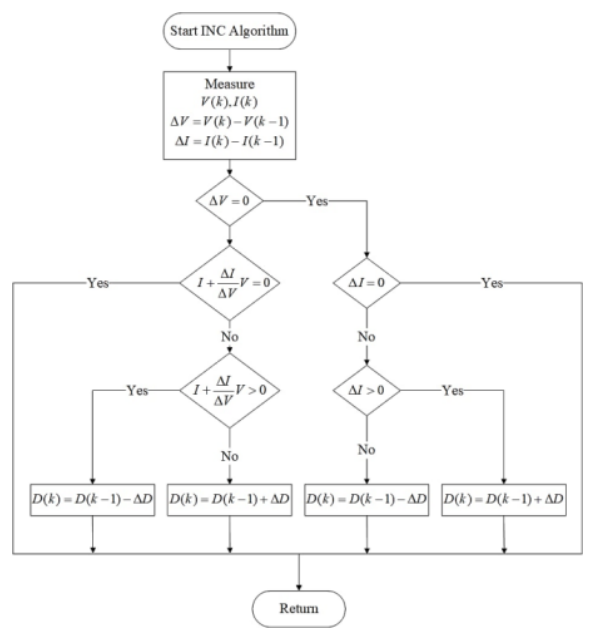

Figure 7: Incremental conductance algorithm [11]

\subsection{Magnetic Circuit}

In switch-mode power supplies designs, the magnetic circuit is a very important key part. It is used to convert electrical energy to magnetic energy. When the switch is on the magnetic core stores the energy and when the switch is off the magnetic energy converts to electrical energy then transferring energy to the output or load as shown in Fig.8 [7].In theory or ideal design, the magnetic circuit or power inductor has no power absorption. But in practice or real application, we found two problems in the magnetic circuits, including magnetic core losses as shown in Fig.8.

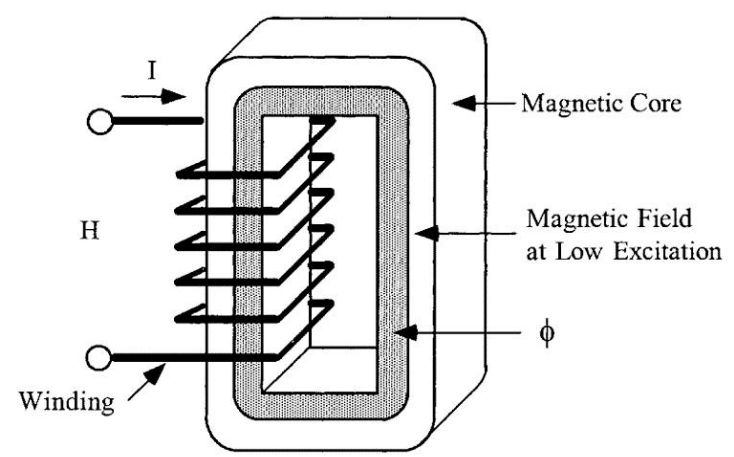

Figure 8: Magnetic Circuit with excitation current [6]

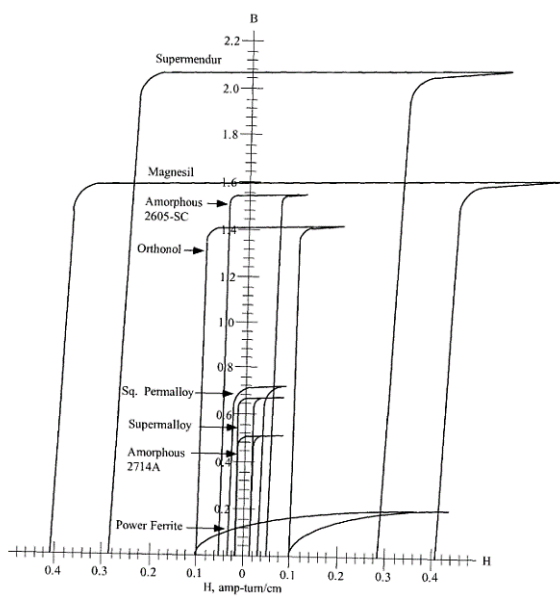

Figure 9: B-H Loops of Magnetic Materials with hysteresis loss level [7]
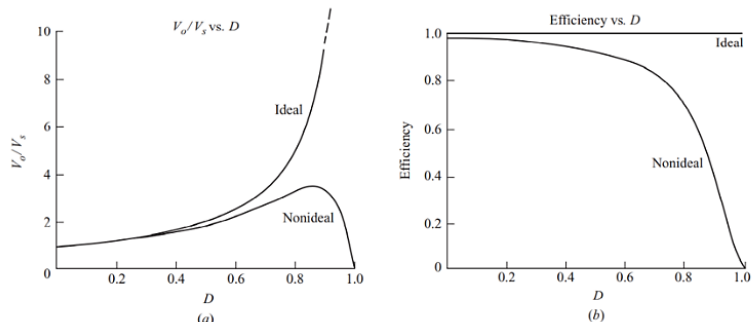

Figure 10: Boost converter for a non ideal inductor. (a) Output voltage; (b) Boost converter efficiency [2] 
The inductor resistance also influences the power efficiency of the converters. Efficiency is the ratio of output power to output power plus losses [2]. For the boost converter as shown in Fig.9 and Fig.10.

\section{PROJECT DESIGNS}

In this project, we use DC-DC MPPT Boost topology with MPPT algorithm as shown in Fig.11.

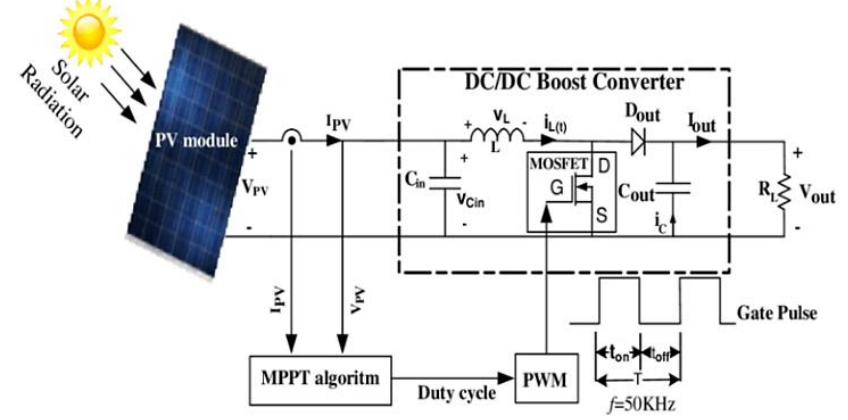

Figure 11: MPPT Solar Converter Diagram

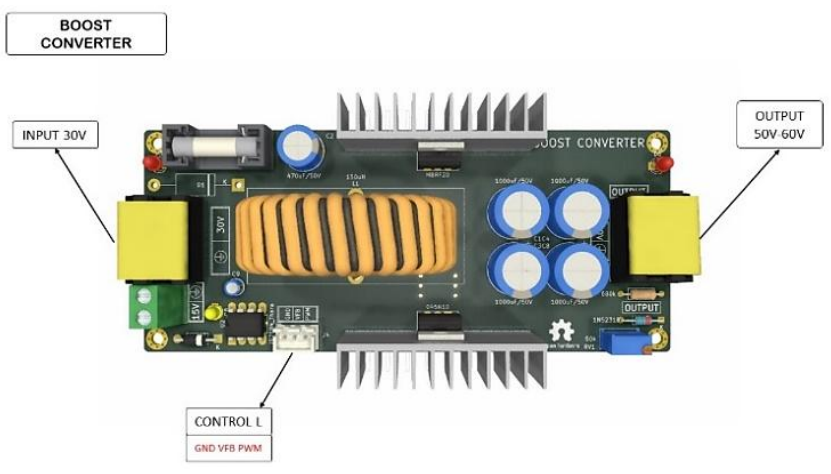

Figure 12: MPPT Boost PCB Prototype

Table 1: Parameter of Boost Converter design

\begin{tabular}{|c|c|c|c|}
\hline No & Parameters & Values & Units \\
\hline 1 & $V_{i n, \min }$ & 12 & $\mathrm{~V}$ \\
\hline 2 & $V_{i n, \max }$ & 40 & $\mathrm{~V}$ \\
\hline 3 & $V_{o}$ & 50 & $\mathrm{~V}$ \\
\hline 4 & $P_{o}$ & 500 & $\mathrm{~W}$ \\
\hline 5 & $F_{s w}$ & 62.5 & $\mathrm{kHz}$ \\
\hline 6 & $\Delta i_{L}$ & $40 \%$ & $\mathrm{~A}$ \\
\hline
\end{tabular}

$$
\begin{gathered}
V_{o}=\frac{V_{s}}{1-D}, I_{L}=\frac{V_{o} I_{o}}{V_{s}} \\
I_{L, \max }=I_{L}+\frac{\Delta i_{L}}{2}=\frac{V_{s}}{(1-D)^{2} R}+\frac{V_{s} D T}{2 L}
\end{gathered}
$$

$$
\begin{gathered}
I_{L, \min }=I_{L}-\frac{\Delta i_{L}}{2}=\frac{V_{s}}{(1-D)^{2} R}-\frac{V_{s} D T}{2 L} \\
L=\frac{V_{s} D T}{\Delta i_{L}}=\frac{V_{s} D}{\Delta i_{L} f}, \quad C=\frac{D}{R f\left(\frac{\Delta V_{o}}{V_{o}}\right)}
\end{gathered}
$$

\subsection{Power Inductor and Wire size Design}

Based on the control frequency requirement in table1, the magnetic iron powder core-T130-26 is selected for power inductor design with single copper wire as seen Fig.12. The inductance and winding of the wire can be calculated using Equation 5 and the wire diameter for current conducting can be calculated using Equation 6.

$$
\begin{gathered}
L=\frac{A_{L} \times N^{2}}{100}, N=\sqrt{\frac{L \times 100}{A_{L}}} \\
A=\frac{\pi D^{2}}{4}, D=\sqrt{\frac{A \times 4}{\pi}}
\end{gathered}
$$

The magnetic core selection for the operating frequency is selected using the data from Fig.13.
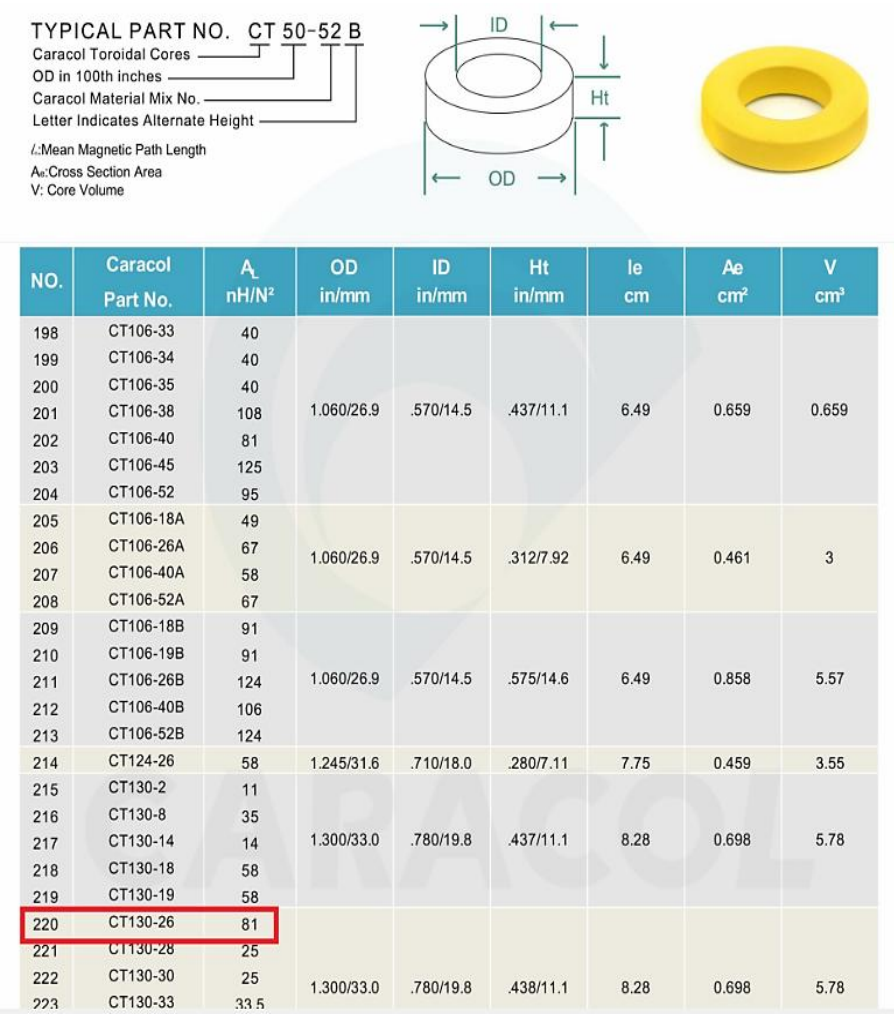

Figure 13: Iron powder data selection 
ISSN (online): 2581-3048

Volume 6, Issue 1, pp 77-87, January-2022 https://doi.org/10.47001/IRJIET/2022.601015

\subsection{Controller Design}

We use Arduino NANO for applying the control algorithm, creating62.5kHzswitching frequency, duty cycle $50 \%$ for PWM Controller.

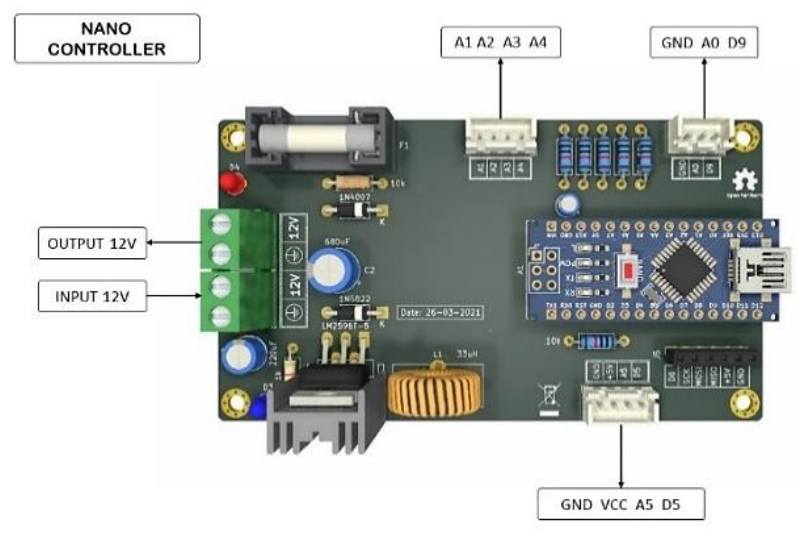

Figure 14: PWM Controller with Arduino NANO

\subsection{MPPT and P\&O Control Algorithm}

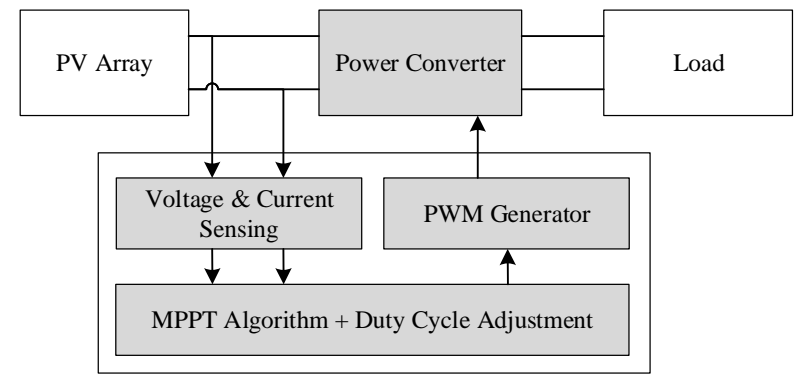

Figure 15: MPPT system block diagram

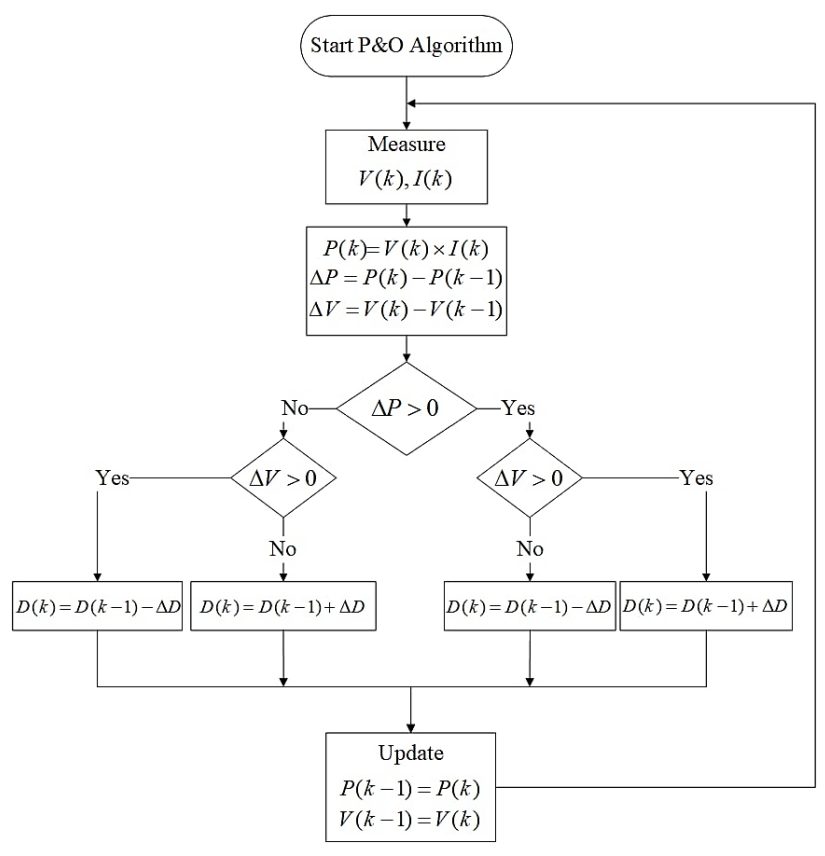

Figure 16: MPPT and P\&O control algorithm

\subsection{Parameter Reader System}

For measuring the PV array voltage and current value, the current sensor module is designed based on the ACS712 current sensor and voltage divider circuit for measuring the PV voltage as shown in Fig.16.

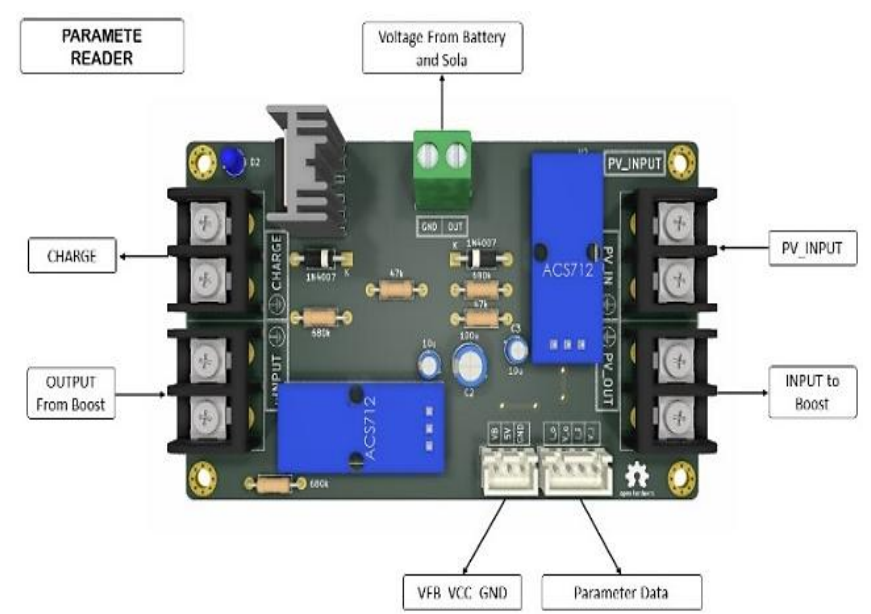

Figure 17: Current and Voltage Sensor with ACS712

\subsection{Data Record and LCD Display}

The monitoring system is used for displaying the information of the MPPT and battery charging mode including the voltage and current reading. This system is designed as a display module shown in Fig.17.

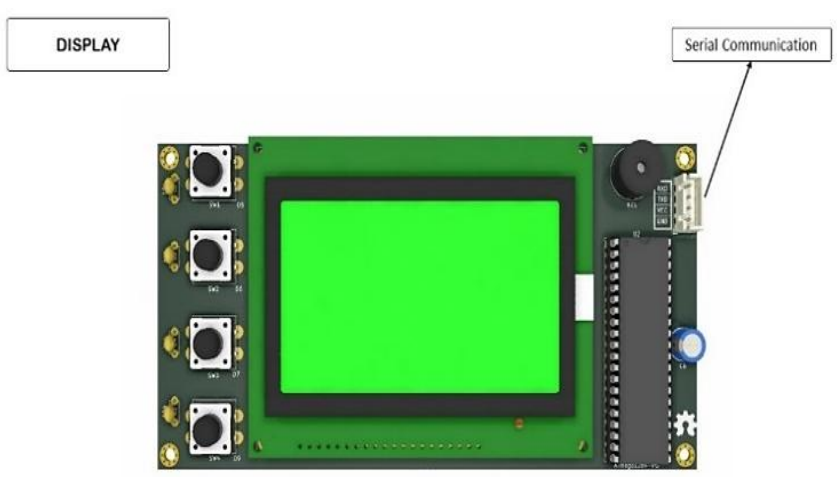

Figure 18: Charging Data Record and Display System

\subsection{MPPT Boost Charging System}

Fig.18 shows the complete system of the MPPT boost charging system. Fig.18 (a) is the main boost converter for stepping up the PV voltage to the battery's charging voltage. For tracking the PV current and voltage the sensor board Fig.18 (b) is used. The Arduino NANO is used for controlling both the MPPT algorithm and battery fast charging methods shown in Fig.18 (c). The data will be shown in the monitoring system board in Fig.18 (d). 
ISSN (online): 2581-3048

\section{IRJIET}

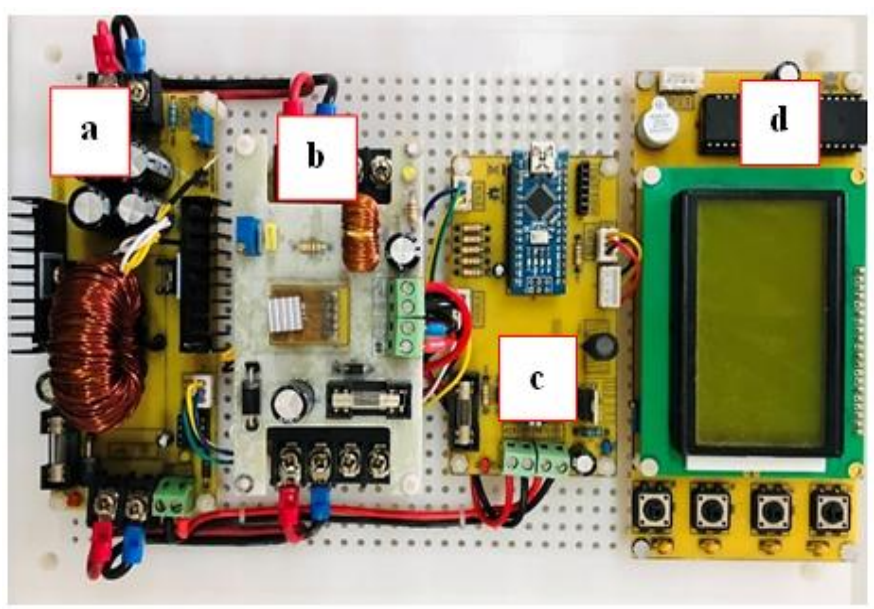

Figure 19: MPPT Boost Charger System

\section{RESULTS AND DISCUSSIONS}

\subsection{Experimental-1 with DC Power Supplies}

In the first analysis of MPPT solar boost charger 48V-10A. We use DC power supplies connected in series-parallel to the variable input voltage from a minimum of $12 \mathrm{~V}$ and maximum of $36 \mathrm{~V}$ ( $30 \mathrm{~W}$ to $300 \mathrm{~W}$ ) power supplies and charge to $48 \mathrm{~V}$ battery as seen in Fig.19.

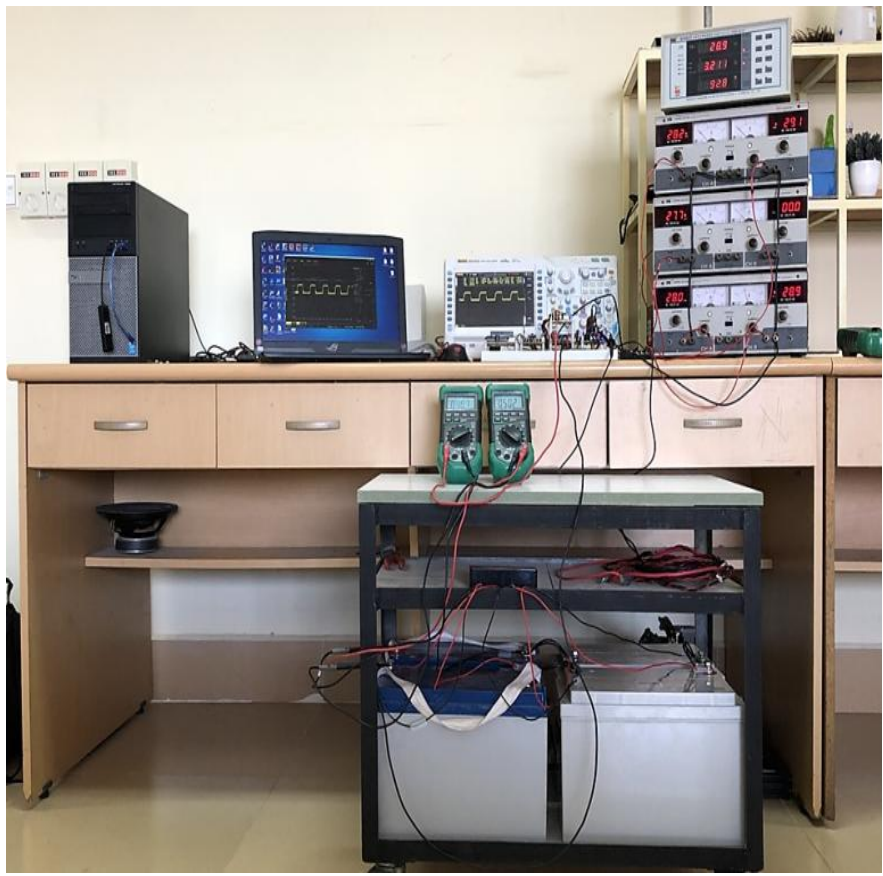

Figure 20: Experimental testing indoor with dc power supplies

To analyze this task, we selected 2 levels of input power as variable PV voltage arrays. When the sunlight changes due to time in a day with power ranging from $30 \mathrm{~W}$ to $300 \mathrm{~W}$ using DC power supplies dual in series-parallel connection as shown in Fig.19.
Volume 6, Issue 1, pp 77-87, January-2022 https://doi.org/10.47001/IRJIET/2022.601015

Tested with power input $30 \mathrm{~W}$ working as Solar PV array
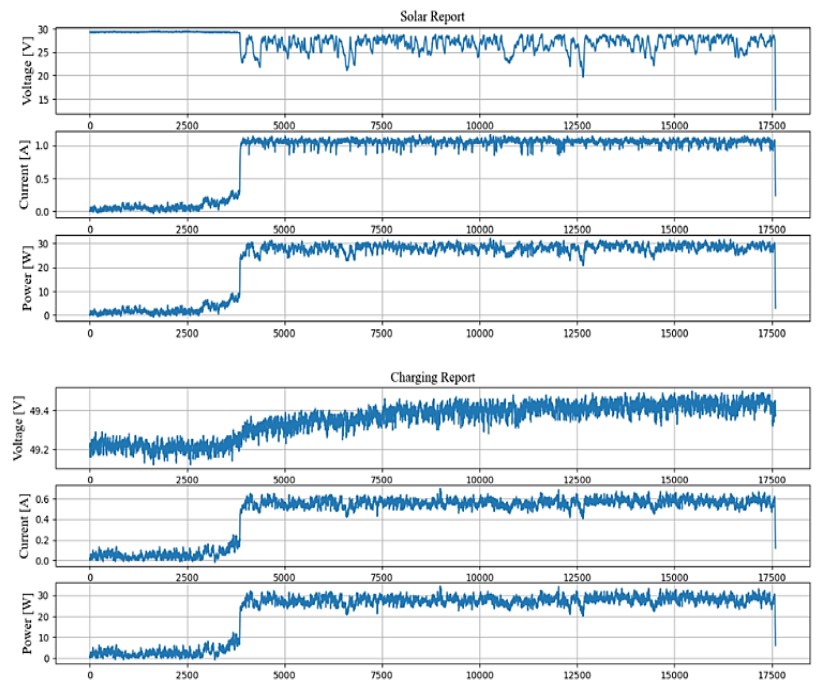

Figure 21: Graph of charging output recorded with input $30 \mathrm{~W}$

Tested with power input $30 \mathrm{~W}$ working as Solar PV array

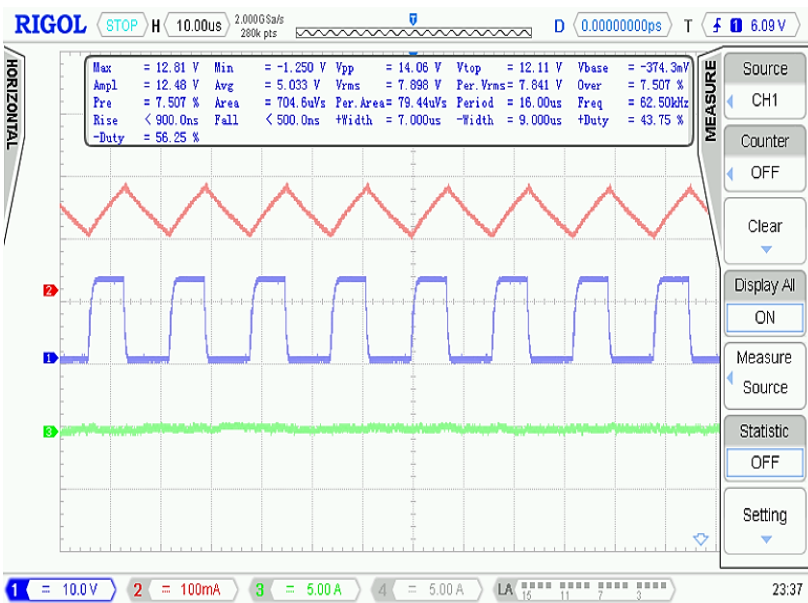

Figure 22: Graph Signal PWM and Inductor current with input 30W

Tested with input power300W working as Solar PV array
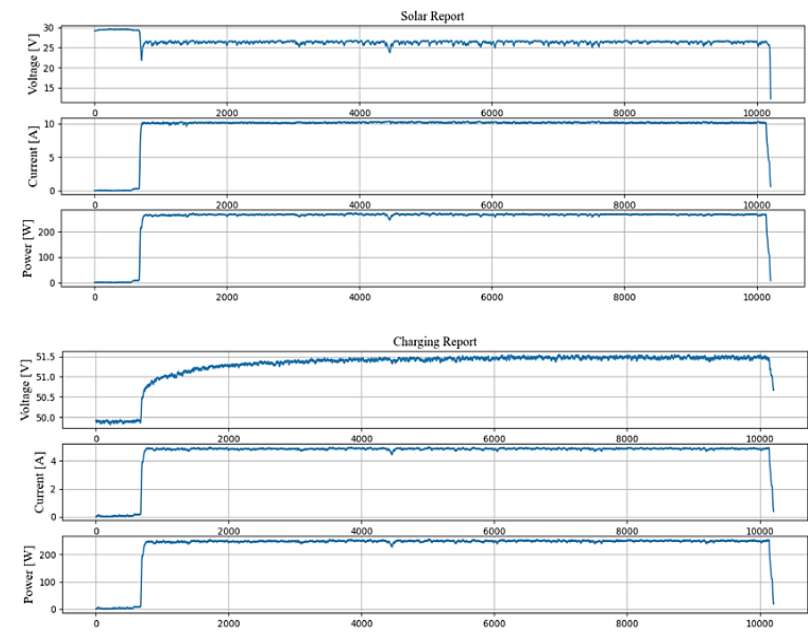

Figure 23: Graph of charging output recorded with input 300W 


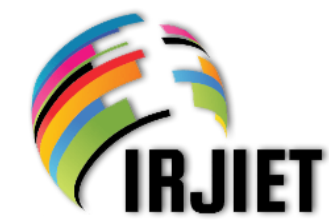

Tested with power input $300 \mathrm{~W}$ working as Solar PV array

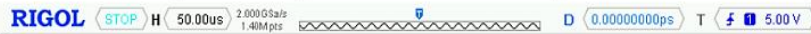

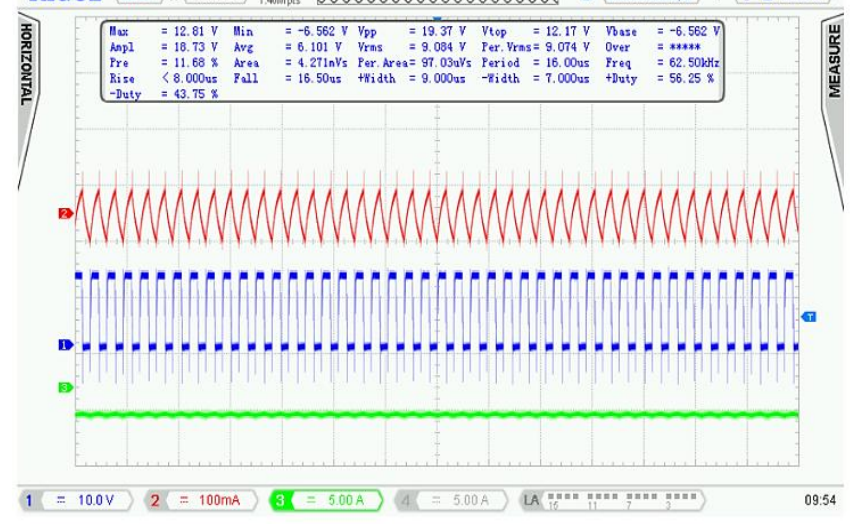

Figure 24: Signal PWM and Inductor current with input 270W

\subsection{Experimental-2 with Solar PV array}

To explore the efficiency of MPPTs Boost Converter with a real solar PV array. We tested with solar PV of $87 \mathrm{~W}, 130 \mathrm{~W}$, $278 \mathrm{~W}$, and $390 \mathrm{~W}$. The outdoor system testing is shown in Fig.24.
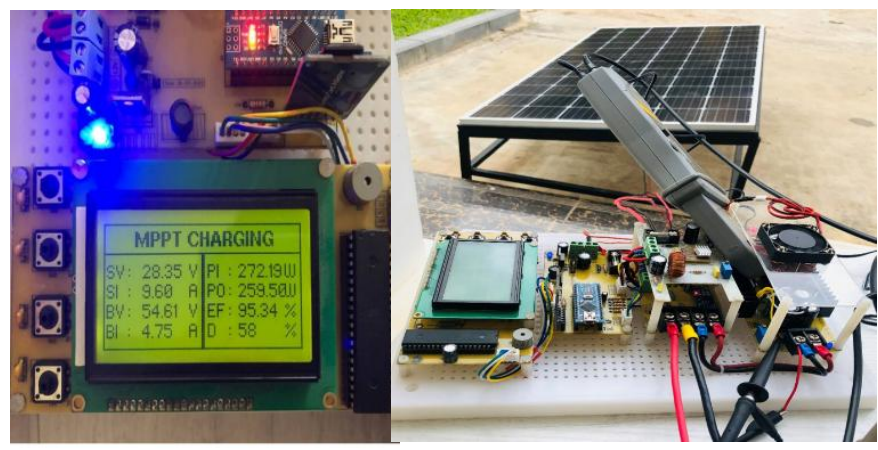

Figure 25: Outdoor Testing with PV array and MPPT Boost Charger

Tested with Solar Kyocera KC85T-87W-17.4V-5.02A(1000W/m2)
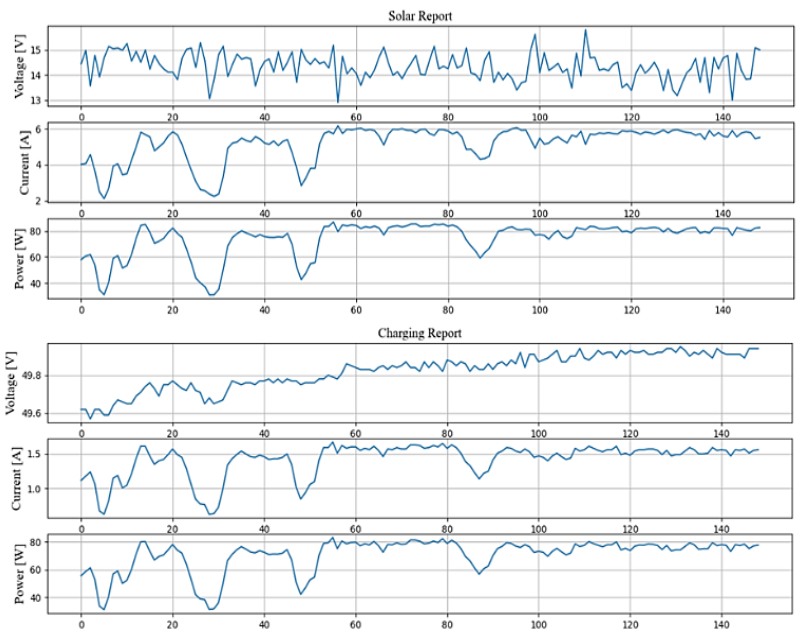

Figure 26: Graph of charging output recorded with Solar 87W
ISSN (online): 2581-3048

Volume 6, Issue 1, pp 77-87, January-2022 https://doi.org/10.47001/IRJIET/2022.601015

Table 3: Result Tested with KC85T-87W-17.4V-5.02A (1000W/m2)

\begin{tabular}{|c|c|c|c|c|c|c|}
\hline No & $=\mathrm{Vs}(\mathrm{V})$ & $=$ Is $(A)$ & Ps (W) & $\neg V_{B}(V)$ & $P c(W)-$ & EIf $(\%)=$ \\
\hline 1 & 14.63 & 5.48 & 80.17 & 49.75 & 76.62 & 95.56 \\
\hline 2 & 14.51 & 5.39 & 78.21 & 49.76 & 75.14 & 96.07 \\
\hline 3 & 14.52 & 5.74 & 83.34 & 19.78 & 79.15 & 94.97 \\
\hline 4 & 14.74 & 5.74 & 84.61 & 49.81 & 80.19 & 94.78 \\
\hline 5 & 14.28 & 5.93 & 84.68 & 49.82 & 78.72 & 92.96 \\
\hline 6 & 14.11 & 5.91 & 83.39 & 49.83 & 78.23 & 93.82 \\
\hline 7 & 13.85 & 6.01 & 83.24 & 49.85 & 78.26 & 94.02 \\
\hline 8 & 14.21 & 5.91 & 83.98 & 49.87 & 78.30 & 93.23 \\
\hline 9 & 15.11 & 5.63 & 85.21 & 19.88 & 80.81 & 94.80 \\
\hline 10 & 14.87 & 5.55 & 82.53 & 49.89 & 78.83 & 95.51 \\
\hline verage & 14.49 & 5.73 & 82.94 & & 78.42 & 94.57 \\
\hline
\end{tabular}

Eff $(\%)$

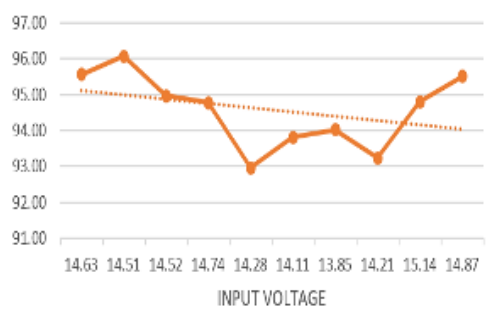

Figure 27: Efficiency due to variable voltage of Kyocera KC85T-87W

Tested with Solar Kyocera KC130GT-130W-17.6V-7.39A(1000W/m2)
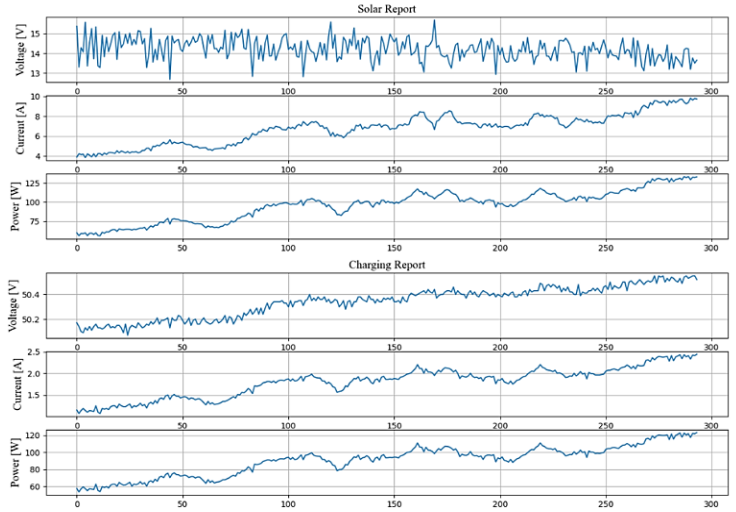

Figure 28: Graph of charging output recorded with Solar 87W

Table 4: Result Tested with KC130GT-130W-17.6V-7.39A(1000W/m2)

\begin{tabular}{|c|c|c|c|c|c|c|}
\hline No $F$ & $\mathrm{~V}_{\mathrm{s}}(\mathrm{V})$ & Is (A) & $F$ Ps (W) & $V_{\text {B }}(v)$ & $-P C:(W)=$ & Eff $(\%)$ \\
\hline 1 & 12.82 & 7.75 & 99.36 & 50.31 & 91.56 & 92.16 \\
\hline 2 & 13.59 & 7.45 & 101.25 & 50.35 & 96.17 & 94.99 \\
\hline 3 & 13.92 & 7.81 & 108.72 & 50.41 & 101.32 & 93.20 \\
\hline 4 & 13.55 & 8.41 & 113.96 & 50.42 & 106.39 & 93.36 \\
\hline 5 & 13.06 & 8.41 & 109.83 & 50.43 & 101.36 & 92.29 \\
\hline 6 & 14.35 & 7.61 & 109.20 & 50.44 & 102.39 & 93.76 \\
\hline 7 & 13.96 & 7.94 & 110.84 & 50.46 & 102.43 & 92.41 \\
\hline 8 & 13.87 & 8.04 & 111.51 & 50.47 & 104.98 & 94.14 \\
\hline 9 & 13.12 & 9,09 & 119.26 & 50.48 & 110.05 & 92.27 \\
\hline 10 & 14.45 & 8.81 & 127.30 & 50.51 & 116.68 & 91.65 \\
\hline Average of & 13.67 & 8.13 & 111.12 & & 103.33 & 93.02 \\
\hline
\end{tabular}

Eff (\%)

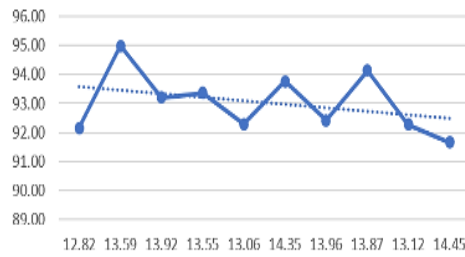

INPUT VOLTAGE

Figure 29: Efficiency due to variable voltage of Kyocera KC130GT-130W 
ISSN (online): 2581-3048

Volume 6, Issue 1, pp 77-87, January-2022

https://doi.org/10.47001/IRJIET/2022.601015

Tested with Solar Sundaya-278W-17.8V*2-0.8A(1000W/m2)

Sohr Report

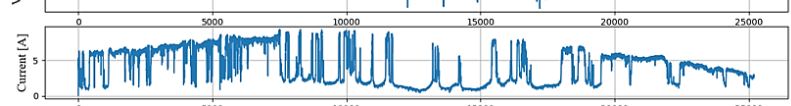

$\underbrace{5000}_{5000}$

charging Report

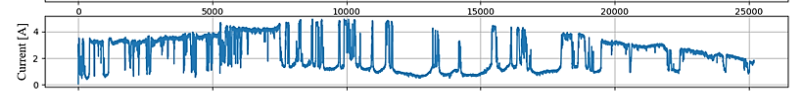

$\underbrace{5000}_{5000}$

Figure 30: Graph of charging output recorded with Solar 278W

Table 5: Result Tested with Sundaya-278W-17.8V*2-0.8A(1000W/m2)

\begin{tabular}{|c|c|c|c|c|c|c|}
\hline No & - Vs (V) & Is $(A)$ & - Ps (W) & $-V_{B}(V)$ & - Pc (W) & Efr (\%) \\
\hline 1 & 29.84 & 6.41 & 191.27 & 51.78 & 181.75 & 95.02 \\
\hline 2 & 30.46 & 6.56 & 199.82 & 51.84 & 190.25 & 95.21 \\
\hline 3 & 29.57 & 7.08 & 209.36 & 51.85 & 199.62 & 95.35 \\
\hline 4 & 29.67 & 7.14 & 211.84 & 51.88 & 200.78 & 94.78 \\
\hline 5 & 28.67 & 8.01 & 229.65 & 51.91 & 218.54 & 95.16 \\
\hline 6 & 30.34 & 7.77 & 235.74 & 51.95 & 222.87 & 94.54 \\
\hline 7 & 28.54 & 8.33 & 237.74 & 51.97 & 223.99 & 94.22 \\
\hline 8 & 29.94 & 8.21 & 245.81 & 51.98 & 232.87 & 94.74 \\
\hline 9 & 29.64 & 8.45 & 250.46 & 52.04 & 235.22 & 93.92 \\
\hline 10 & 30.37 & 8.54 & 259.36 & 52.07 & 245.77 & 94.76 \\
\hline Ave & 2970 & 7.65 & 227.10 & & 215.17 & 94.77 \\
\hline
\end{tabular}

Eff $(\%)$

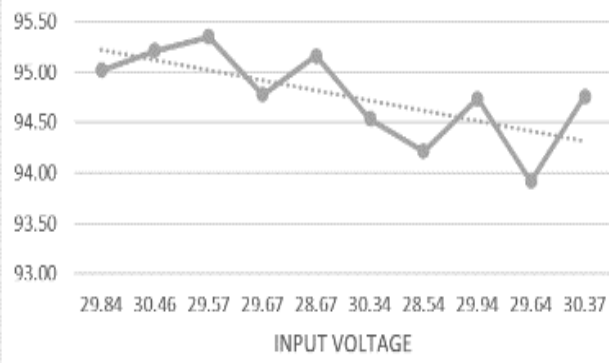

INPUT VOLTAGE

Figure 31: Efficiency due to variable voltage of Kyocera KC130GT-130W

Tested with Solar BESUTO-390W-41.1V-9.49A(1000W/m2)

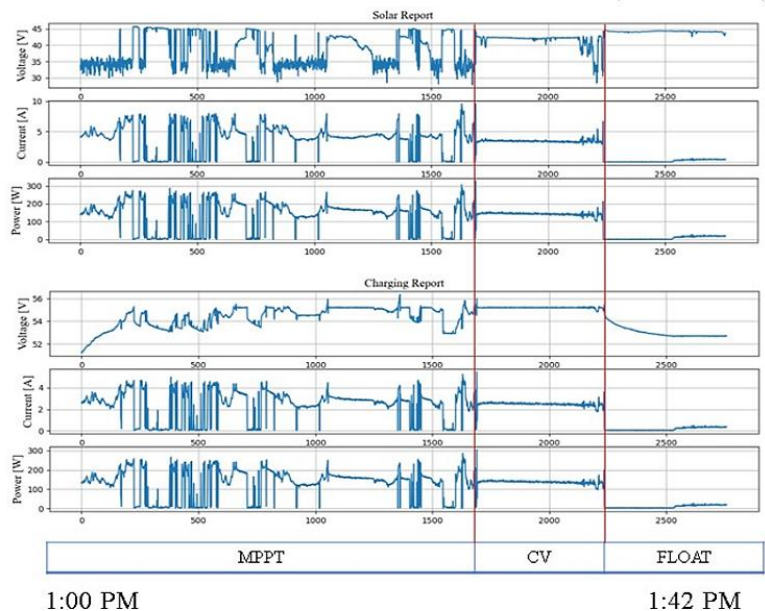

Figure 32: Graph of charging output recorded with Solar 390W

\begin{tabular}{|c|c|c|c|c|c|c|}
\hline No $F$ & Vs (V) & Is (A) & Ps (w) & $V_{B}(V)$ & $\nabla \operatorname{Pc}(\mathrm{W})=$ & EXf $(\%)$ \\
\hline 1 & 29.46 & 9.74 & 286.94 & 52.52 & 275.20 & 95.91 \\
\hline 2 & 31.92 & 9.19 & 302.92 & 52.53 & 293.12 & 96.76 \\
\hline 3 & 30.67 & 9.33 & 286.15 & 52.53 & 266.33 & 93.07 \\
\hline 4 & 36.05 & 8.29 & 298.85 & 52.54 & 287.39 & 96.17 \\
\hline 5 & 35.38 & 8.56 & 302.85 & 52.54 & 294.75 & 97.32 \\
\hline 6 & 34.21 & 9,43 & 322.60 & 52.54 & 306.31 & 94.95 \\
\hline 7 & 32.94 & 9.74 & 320.84 & 52.55 & 307.42 & 95.82 \\
\hline 8 & 35.26 & 9.21 & 324.74 & 52.55 & 310.57 & 95.61 \\
\hline 9 & 32.92 & 9.39 & 309,12 & 52.55 & 290.60 & 94.01 \\
\hline 10 & 33.18 & 8.87 & 294.31 & 52.55 & 284.82 & 96.78 \\
\hline Average of & 33.199 & 9.205 & 304.93 & & 291.65 & 95.64 \\
\hline
\end{tabular}

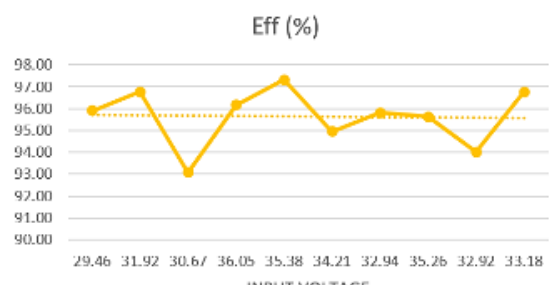

INPUT VOLTAGE

Figure 33: Efficiency due to variable voltage of BESUTO-390W

Tested with Solar BESUTO-390W-41.1V-9.49A(1000W/m2)
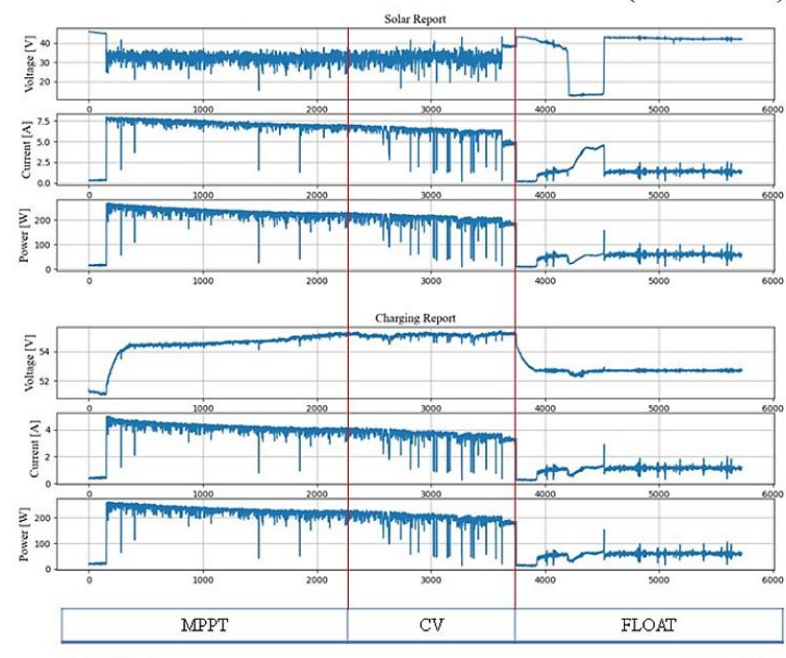

2:00 PM

4:00 PM

Figure 34: Graph of charging output recorded with Solar 390W

Tested with Solar BESUTO-390W-41.1V-9.49A(1000W/m2)

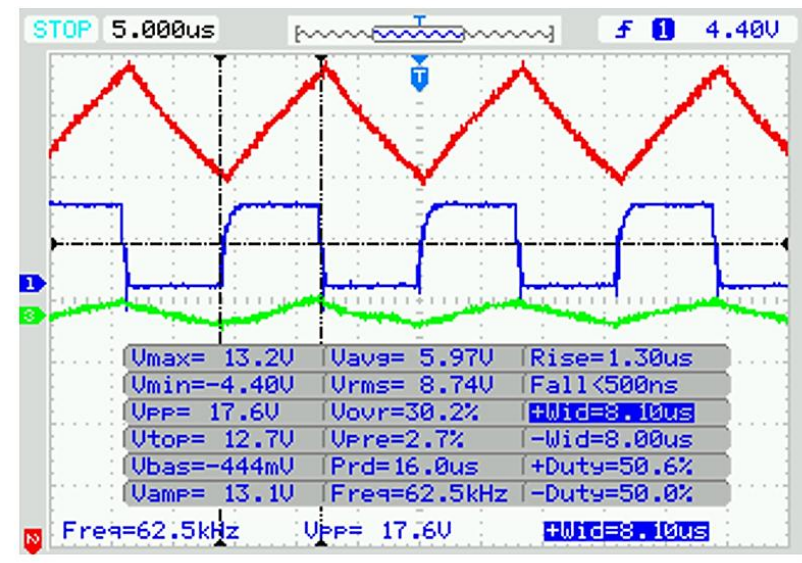

Figure 35: Signal on MPPT Charging Stage 
Tested with Solar BESUTO-390W-41.1V-9.49A(1000W/m2)

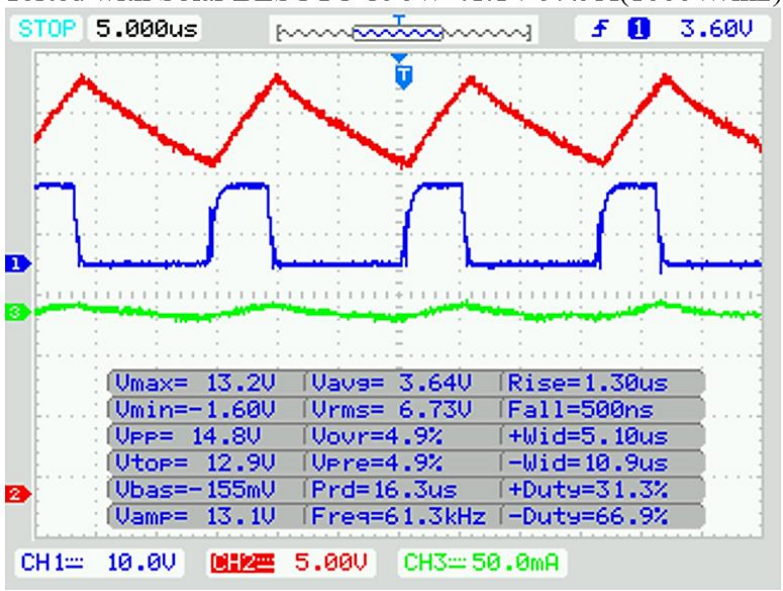

Figure 36: Signal on CV Charging Stage

Tested with Solar BESUTO-390W-41.1V-9.49A(1000W/m2)

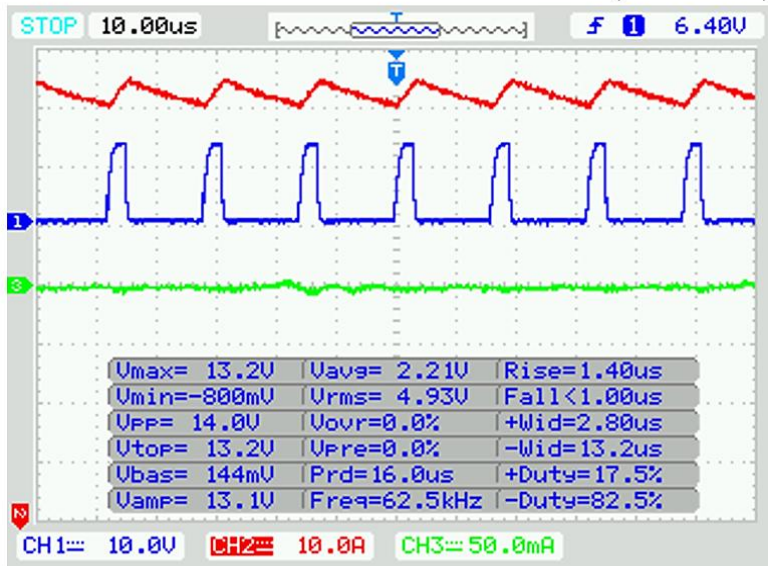

Figure 37: Signal on Float Charging Stage

\section{CONCLUSION}

Based on experimental results of our MPPT solar charger design with boost topology and P\&O control algorithm. We can achieve an efficiency of up to $95 \%$ with a variable input voltage from $29 \mathrm{~V}$ to $36 \mathrm{~V}$ using the BESUTOSolar390W41.1V9.49A ( $1000 \mathrm{~W} / \mathrm{m}^{2}$ ) including the sunlight's irradiance changes during daytime. This design method is possible for application on hybrid onboard Charger for Sustainable Energy of 3-Wheel Solar E-Rickshaw and Electric Vehicles. The output and outcome of this project can be comfortable for customers with the clean energy system, can be charged anywhere, saving time, green energy source, clean city, no emission transportation, and economic saved. Also, a good technology for electric vehicle systems.

\section{ACKNOWLEDGEMENT}

First, I would like to say big thanks to his excellency Dr. BUN Phearin, the President of NPIC, and his excellency Mr.
MOUNG Phasy, the Vice President of NPIC always trusting and supporting Ph.D. Scholarship to me.

Second, I would like thanks to my supervisor Dr. AM SokChea Deputy Head of Electrical and Energy. And CoSupervisors Dr. KIM Bunthern \& Dr. CHRIN Phok, Head \&member of Energy Technology and Management (ETM) always give me very good comments and ideas on studying in this project.

And third, I am very much thankful to all authors of Boost converter topologies, MPPT algorithms, P \& O algorithms, Magnetic Circuit Design, and MPPT-CV\& Float Charging Methods for completing work on my research topic and thesis.

\section{REFERENCES}

[1] Energy Efficiency \& Renewable Energy, "AllElectric Vehicles" Alternative Fuels Data Center: How Do All-Electric Cars Work? (energy.gov).

[2] Daniel W. Hart Valparaiso University Valparaiso, Indiana, "DC-DC Converters" Power Electronics. Copyright (C) 2011 by The McGraw-Hill Companies.

[3] Texas Instruments "Power Topologies Quick Reference Guide" (C 2016 Texas Instruments Incorporated Printed in Belgium by Harte Hanks.

[4] Jimmy Joseph, Prof. Rakesh M Patel, Dr. Hardik R Pathak "Analysis and Comparison of DC/DC Converter Topologies for the Design and Development of a Solar Based Inverter Less System" Proceedings of the 2nd International Conference on Electronics, Communication, and Aerospace Technology (ICECA 2018).

[5] MPPT Algorithm - MATLAB \& Simulink (mathworks.com) Power Electronics Control Design with Simulink W. Khan, A. H. Abdullah, M. H. Anisi, and J. I. Bangash, "A comprehensive study of data collection schemes using mobile sinks in wireless sensor networks," Sensors, vol. 14, no. 2, pp. 25102548, 2014.

[6] Colonel Wm. T. McLyman“'Chapter1 Fundamentals of Magnetics", Transformer and Inductor Design Handbook Fourth Edition. @2011 by Taylor and Francis Group, LLC .

[7] Colonel Wm. T. McLyman"Chapter2 Magnetic Materials and Their Characteristics" Transformer and Inductor Design Handbook Fourth Edition. @2011 by Taylor and Francis Group, LLC.

[8] Colonel Wm. T. McLyman "Transformer and Inductor Design Handbook Fourth Edition”. @2011 by Taylor and Francis Group, LLC.

[9] W. G. Hurley. W. H. Wolfle "Transformer and Inductor Design for Power Electronics." Theory, 
ISSN (online): 2581-3048

Design, and Application. This edition was first published @2013 John Wiley \& Sons Ltd.

[10] Robert W. Erickson. Dragan Maksim Vic "Magnetic/ Inductor Design" Fundamentals of Power Electronics Second Edition. Print (C2001 Kluwer Academic/Plenum Publishers. New York.

[11] Salman Salman, Xin $\mathrm{AI}^{*}$ and Zhouyang WU, "Design of a P\&O algorithm based MPPT charge controller for a stand-alone 200W PV system," Salman et al. Protection and Control of Modern Power Systems (2018) https://doi.org/10.1186/s41601-018-0099-8

[12] Murari Lal Azad; Soumya Das; Pradip Kumar Sadhu; BiplabSatpati; Anagh Gupta; P. Arvind, "P\&O algorithm based MPPT technique for solar PV System under different weather conditions," 2017 International Conference on circuits Power and Computing Technologies [ICCPCT].

[13] D. K. Sharma; G. Purohit, "Advanced perturbation and observation $(\mathrm{P} \& \mathrm{O})$ based maximum power point tracking (MPPT) of a solar photo-voltaic system," 2016 51st International Universities Power Engineering Conference

(UPEC)

DOI: 10.1109/UPEC39679.2016/6-9 Sept. 2016.

[14] Fang Lin Luo Hong Ye Muhammad Rashid, "Digital Power Electronics and Applications," Copyright (C) 2005, Elsevier (USA). All rights reserved.

[15] MARIAN K. KAZIMIERCZUK Wright State University Dayton, Ohio, USA, "Pulse-width Modulated DC-DC Power Converters," This edition first published 2008 John Wiley \& Sons, Ltd.

[16] Marty Brown "Power Supply Cookbook," Second Edition, Newness is an imprint of ButterworthHeinemann. Copyright (C) 2001 by ButterworthHeinemann.

[17] ON Semiconductor "Switch Mode Power Supply Reference Manual and Design Guide" SMPSRM/D Rev. 1, Sept-1999.

\section{AUTHORS BIOGRAPHY}

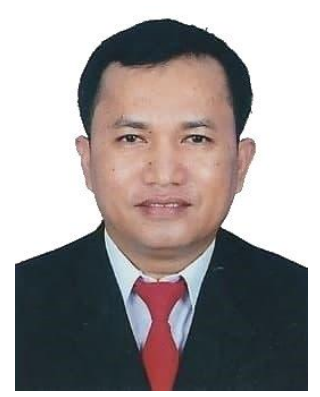

MEAS Saran, The present is a Ph.D. Candidateof Energy Technology and Management at ITC, Phnom Penh, Cambodia. MSc. Eng. of Electrical and Electronics Eng. in Power Electronics from JEONJU University, South Korea, 2013 and Bachelor of Technology in field of Electrical Engineering at National Institute of Cambodia (NPIC) 2009. Current work is as a Deputy Head of Electronic Faculty of NPIC and Adviser of NPIC's Power Electronics and EVs LAB.
https://doi.org/10.47001/IRJIET/2022.601015

Phnom Penh, Cambodia.

Tell: (+855) 95754234

Email: saranagoldd@gmail.com

meassaran@npic.edu.kh

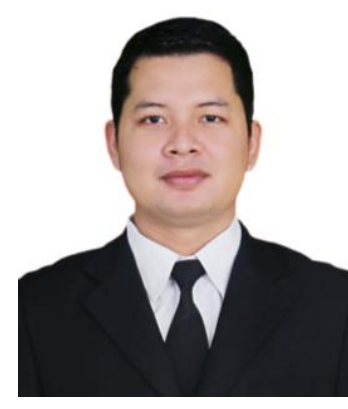

SRUN Channareth, received his B.Eng. degree in Electronics Engineering from the National Polytechnic Institute of Cambodia, Cambodia, in 2012 and a Master of Eng. degree in Electrical Engineering from Universitas Hasanuddin, Indonesia in 2018. $\mathrm{He}$ is currently a lecturer at the Department of Electronic Engineering NPIC and his research interests are motor controller based on microcontroller and FPGA, power electronics for renewable energy systems, especially photovoltaic systems.

UN Sokoeun, The present is a $\mathrm{Ph}$.D. Candidate in Mechanics and Information Technology, at the Institute of Technology of Cambodia, Phnom Penh,

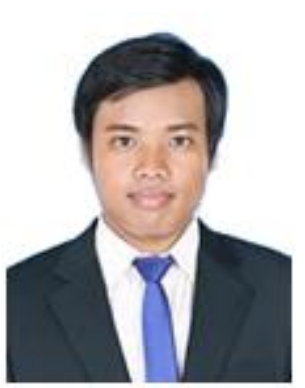
CAMBODIA. MS. Electrical and Telecommunication System Eng. at the University of Soon Chun Hyang, South Korea in 2013. Bachelor's degree of Technology in Electronics Eng. at the National Polytechnic Institute of Cambodia (NPIC), 2009.

Current work is a Telecommunication Dept. Head and an advisor of Telecommunication LAB, Phnom Penh, CAMBODIA.

Tel: (+855) 12563553

Email: unsokoeun@npic.edu.kh

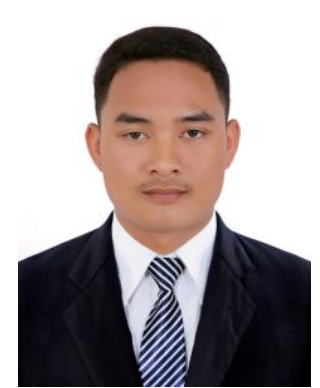

SON Thara, Present is NPIC's Power Electronics LAB Assistant and a Bachelor student of Electronic Engineering, National Polytechnic Institute of Cambodia (NPIC), Phnom Penh, Cambodia.

Tel: $(+855) 767974707$

Email: sonthara2014@gmail.com 
NY Virbora, Present is NPIC's Power Electronics LAB Assistant and a Lecturer of Electronics Faculty, National Polytechnic Institute of Cambodia (NPIC), Phnom Penh, Cambodia.

Tel: (+855) 968916954

Email: nyvirakbora@gmail.com

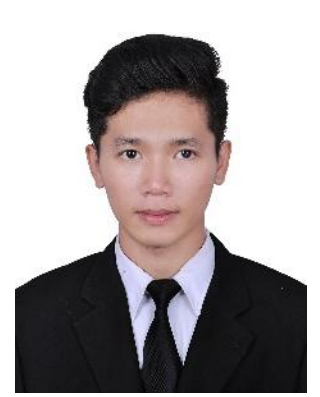

SRIM Saravuth, Present is NPIC's Power Electronics LAB Assistant and a Lecturer of Electronics Faculty, National Polytechnic Institute of Cambodia (NPIC), Phnom Penh, Cambodia.

Email: srimsaravuth@gmail.com

\section{Citation of this Article:}

MEAS Saran, SRUN Channareth, UN Sokoeun, Son Tara, NY Virbora, SRIM Saravuth, “Optimization of an Integrated Hybrid Onboard Charger with High Efficiency of MPPT Solar Charger for Sustainable Energy of 3-Wheel Solar E-Rickshaw and Electric Vehicles", Published in International Research Journal of Innovations in Engineering and Technology - IRJIET, Volume 6, Issue 1, pp 77-87, January 2022. Article DOI https://doi.org/10.47001/IRJIET/2022.601015 